\title{
Residências artísticas e currículo-experimentação: como podem nos ajudar a adiar o fim do mundo ${ }^{1}$
}

\section{Artistic residencies and curriculum- experimentation: how can they help us to postpone the end of the world?}

\section{Residencias artísticas y currículo-experimentación: ¿cómo pueden ayudarnos a retrasar el fin del mundo?}

Fabíola Fonseca ${ }^{2}$

Antônio Carlos Rodrigues de Amorim ${ }^{3}$

DOI: http://dx.doi.org/10.20435/serie-estudos.v26i58.1592

\begin{abstract}
Resumo: Diante de um cenário urgente posto pelas mudanças climáticas, questionamos e pensamos, junto de Ailton Krenak e pesquisadores da filosofia da diferença, em como um currículo outro pode nos ajudar a adiar o fim do mundo. Trazemos para essa conversa as experimentações que temos feito com as residências artísticas nos laboratórios de pesquisa como possibilidade de traçar linhas de fuga, que inspiram compor currículos. Assim, experimentar é o que nos abre para as potências das coisas e o que tem nos ajudado a encontrar aberturas para outras biologias possíveis e outras formas de nos relacionarmos com espécies humanas e não humanas, seres vivos e não vivos.
\end{abstract}

Palavras-chave: currículo; residência artística; mudanças climáticas.

Abstract: Faced with an urgent landscape imposed by climate change, we question and think, with Ailton Krenak and researchers from philosophy of difference, on how another curriculum can help us to postpone the end of the world. We bring to this conversation the experimentations that we

\footnotetext{
${ }^{1}$ Este trabalho foi financiado pela Fundação Cearense de Apoio ao Desenvolvimento Científico e Tecnológico (FUNCAP-CE) e pelo Instituto Nacional de Ciência e Tecnologia para Mudanças Climáticas (INCT-MC) Fase 2, com financiamento do CNPq Processo 465501/2014-1, FAPESP Processo 2014/50848-9 e da Coordenação de Aperfeiçoamento de Pessoal de Nível Superior (CAPES) Processo 16/2014.

2 Universidade Federal do Ceará (UFC), Fortaleza, Ceará, Brasil. Pós-doutoranda UFC.

${ }^{3}$ Universidade Estadual de Campinas (Unicamp), Campinas, São Paulo, Brasil. Pesquisador $1 \mathrm{~B}$ do CNPq.
} 
have done with artistic residences into a biology laboratories as a possibility to trace line off light able to compose the curricula. Thus, to experiment is what can open us to potency of things and it has helped us to find openings to other possible biologies and other ways to relate between human and non-human species, living beings and non-living beings.

Keywords: curriculum; artistic residency; climate changes.

Resumen: Ante un escenario urgente que plantea el cambio climático, cuestionamos y pensamos, junto a Ailton Krenak e investigadores de la filosofía de la diferencia, en como un currículum otro puede ayudarnos a posponer el fin del mundo. Traemos a esta conversación los experimentos que venimos realizando con residencias artísticas en laboratorios de investigación como posibilidad de trazar líneas de fuga, que inspiran a componer currículos. Entonces, experimentar es lo que nos abre a la potencia de las cosas y lo que nos ha ayudado a encontrar aperturas a otras posibles biologías y otras formas de relacionarnos con especies humanas y no humanas, seres vivos y no vivos.

Palabras clave: curriculum; residencia artística; cambio climático.

\section{ENUNCIANDO O PROBLEMA: BREVES COMEÇOS}

A questão que levantamos com este texto é: como as mudanças climáticas nos colocam diante da necessidade de um currículo outro? Questionamos isso porque parte da crise ambiental vem também das formas como temos sido forjados a nos relacionar com a natureza, esquecendo inclusive que somos ela. E nosso desafio diante disso é também de como criar outras formas de nos relacionarmos com o outro, sejam seres vivos, sejam seres não vivos. "Talvez o desafio maior seja o de criar novas formas de relação com o outro, seja qualquer outro, humano, animais, plantas, minerais e até mesmo as máquinas. Propor um pacto, uma convenção em prol de um mundo mais sustentável" (SILVA, 2020, p. 193).

Isso nos remete a pensar a experimentação artística como possibilidade de tatear um currículo-nômade. Pensamos que essa pode ser uma oportunidade de encontro com esse outro, com a qual temos também a oportunidade de despertar com e para eles, sobretudo quando pensamos isso dentro de um cenário marcado por uma grande crise ambiental. Ailton Krenak fala sobre as mesmerizações que têm sido tomadas como quase regras para nos relacionarmos com a natureza, cuja força propulsora é sempre um critério de utilidade, de como aquilo torna-se uma mercadoria com agregado valor monetário. E, nessa discussão, ele diz que estamos caminhando para o fim do mundo.

Krenak tem-se esforçado em fazer ressonâncias com suas ideias para adiar o fim do mundo e, para ele, adiamos cada vez que a gente investe em criações, em outras danças, outras músicas, outras histórias para contar. 
Nosso tempo é especialista em criar ausências: do sentido de viver em sociedade, do próprio sentido da experiência da vida. Isso gera uma intolerância muito grande com relação a quem ainda é capaz de experimentar o prazer de estar vivo, de dançar, de cantar. E está cheio de pequenas constelações de gente espalhadas pelo mundo que dança, canta, faz chover. O tipo de humano zumbi que estamos sendo convocados a integrar não tolera tanto prazer, tanta fruição de vida. Então, pregam o fim do mundo como uma possibilidade de fazer a gente desistir dos nossos próprios sonhos. $\mathrm{E}$ minha provocação é exatamente sempre poder contar mais uma história. Se pudermos fazer isso, estaremos adiando o fim do mundo. (KRENAK, 2019, p. 26-27).

Nesse texto, queremos pensar com Krenak algumas ideias para um currículo que contribua em adiar o fim do mundo. É pensar como um currículo nos desloca de fórmulas organizadas previamente sobre o que devemos ensinar e aprender. Aliás, é um currículo que coloca em xeque, como dizem Carvalho e Gallo (2010), esse fetichismo que existe em torno disso de que alguém ensina e alguém aprende. Falamos, portanto, de um currículo que vem dos deslocamentos, de aberturas: rizomático. Um espaço com possibilidades de experimentações, que aliás, só acontece com e por elas. Para Kroef (2018, p. 121),

O currículo-nômade é rizomático, excêntrico, engendrando um rizoma na imagem do pensamento. Não há uma unidade principal, uma raiz. As raízes conectam-se e transbordam. Qualquer ponto desse currículo pode ser conectado a qualquer outro, diferente do currículo-programa que, enquanto arborescência, fixa um ponto, uma organização. Não existem pontos ou posições no currículo rizomático, mas linhas e estas linhas não param de se remeterem a outras. Uma das características do currículo rizomático é a de ter múltiplas entradas. Ele não começa nem conclui, ele se encontra sempre no meio. E é no meio que os conceitos adquirem velocidade, numa direção perpendicular, num movimento que os carrega um e outro.

Em consonância com isso, Holzmeister, Silva e Delboni (2016, p. 421) adensam a discussão interessada no campo de estudos curriculares, ao indicarem que "[...] o nômade encarna o sonho, o desejo de uma busca permanente, foge das âncoras e dos ancoradouros, do pensamento com imagem, fica bem longe do pensamento dogmático e dos clichês. Corre, tenta escapar das grades curriculares, dos aprisionamentos avaliativos".

Estamos falando, portanto, de um currículo que experimenta, que se faz no acontecer, nos fluxos engendrados entre os envolvidos naquele momento em que 
acontece. Outros possíveis, outros modos de liberar a vida das suas figurações previsíveis. Um currículo que aposta nos encontros, acontecimentais e heterogêneos. O que nos faz recordar das palavras de Orlandi (2014, s.p.), quando afirma que há sempre algo de extraordinário no encontro: "[...] todo encontro ordinário, portanto, está exposto à possibilidade de uma reviravolta instantânea que pode projetar tudo para fora dos eixos. É como se a própria vida se sentisse abalada por esse vinco em que uma experiência ordinária é dobrada junto a outra, a extraordinária". O desconhecido é algo que nos permite o encontro e o encontro, este também é uma troca ou, nas palavras de Carvalho e Gallo (2010, p. 297), "[...] o aprendizado é um encontro".

Haveria, portanto, "[...] uma dimensão ética importante nesse universo da experimentação" (VINCl, 2018, p. 332) que despertaria em nós potências de agir. E como não sabemos de antemão nossas possíveis conexões com as coisas, resta-nos experimentar com elas a fim de ampliar nossas relações, nossas conexões e emancipar nossas possibilidades de pensar. E Mia Couto (2011, p. 101) é bem assertivo quando fala do desconhecido como uma possibilidade para sermos felizes: "[...] trata-se, sim de possuirmos instrumentos para sermos felizes. E o segredo é estar disponível para que outras lógicas nos habitem, é visitar e sermos visitados por outras sensibilidades".

A forma como temos nos proposto a experimentar esse currículo outro é atravessado pela arte, com as residências artísticas que temos feito nos laboratórios de pesquisa em biologia como possibilidade de, ao adentrar no desconhecido, abrir nossos sentidos para outras biologias. Uma biologia menos utilitarista em que cabe o encantamento. E, quando falamos em encantamento, estamos falando de partículas que nos movimentam nesse processo e que fazem também protocolos obsoletos brilharem aos nossos olhos. Por exemplo, no livro de artista Escalas cromáticas para moscas e seres afins, com previsão de lançamento em outubro de 2021, tomamos como lição a poesia de Manoel de Barros para falar dos protocolos obsoletos que encontramos durante a residência artística no laboratório de genética da Universidade Federal de Uberlândia (UFU).

As coisas que não levam a nada

têm grande importância

Cada coisa ordinária é um elemento de estima.

(Manoel de Barros - Matéria de poesia, no prelo). 
São protocolos obsoletos, esquecidos nas gavetas, aqueles que já não servem para nada, que colocam aos/às cientistas a necessidade da criação de outros protocolos e que nos colocou diante da necessidade de criar um livro para falar deles. Abrir uma gaveta da bancada do laboratório (mesmo que seja no dia da faxina) e descobrir ali as coisas obsoletas como protocolos, instrumentos, vidrarias, papéis e anotações esquecidas. Saber que as coisas nãos servem para nada é saber que elas foram retiradas da utilidade que foi dada a elas, da significância, e é assim, somente assim, que tateamos a potência das coisas: experimentando com elas. Talvez essa seja uma das grandes lições que a ciência, a arte, a filosofia e a poesia nos dão: a de nos colocar em intimidade com as coisas. Uma intimidade que vem do encontro, da experimentação.

A conversa que trazemos para este texto são movimentações vindas das residências artísticas feitas nos laboratórios de pesquisa, as quais vão ao encontro disso que nomeamos de currículo outro e que nos coloca diante dessa questão levantada por Amorim (2020, p. 407):

O currículo em suas textualidades e escritas merece ser olhado como um espaço tempo de efetuação de outros possíveis que não perpetuem a reprodução, o ideal do mesmo e a tomada de posição frente à vida a partir de ideias moralizantes, intolerantes e universais. Haveria espaço para uma transição entre o currículo territorializante, aquele que finca os pés novamente em certos tipos de delimitação e margens, para o currículo aberrante?

Pensando nisso, destacam-se algumas das obras feitas até então: Bactérias transgênicas (2017), Protocolo fungo (2019), Proliferações (2019), Moscas transgênicas (2019) e um livro de artista chamado Manual de como fazer sua mosca transgênica (2019). A cada obra, encontra-se com uma outra biologia: aliás, já não se consegue mais falar em biologia, e sim em biologias. E esse texto nasce disso: desse encontro com a arte que acontece também pelas residências artísticas e que nos tem feito pensar em outras biologias e nesse encontro com o currículo. É que "[...] a vida, como confirmam os movimentos aberrantes, não se restringe a produzir organismos, tampouco se limita à forma orgânica. Esses movimentos atestam uma força inorgânica da vida que atravessa o organismo vivo indiferente a sua integridade" (AMORIM, 2020, p. 408). Uma vida que pulsa para além dos seus limites, que transborda e nos inspira com essas outras biologias. Movimento próximo a Silva e Amorim (2020, p. 328), de “[...] montar um arquivo-laboratório, 
coágulo da experimentação e do experimento, é singular: parte e se instaura no encontro com obras e práticas artísticas, em diferentes espaços e lugares, que dizem ao colecionador algo inusitado sobre natureza".

Portanto, o que escrevemos neste artigo são rasgos de como temos pensado nas residências artísticas como possibilidades de traçar linhas de fuga, da forma como elas têm nos movimentado a pensar e como têm nos ajudado a encontrar outras biologias que compõem um currículo outro. Focaremos no envolvimento intensivo com as criações artísticas que temos feito que conjugam ciência e arte. Essas criações começam com residências artísticas dentro de um laboratório de pesquisa científica, em que me $\mathrm{e}^{4}$ aproximo de cientistas, das pesquisas, dos protocolos científicos, do processo de criação do conhecimento científico, para criar obras de arte. Para tanto, iniciaremos com as discussões sobre as formas que têm sido forjadas para nos relacionarmos com a natureza, sobretudo nessa movente paisagem atravessada pelas mudanças climáticas. Isso porque nossa atual residência artística está inserida nisso: criar uma obra de arte que desperte nossos sentidos em relação ao que está posto pelas mudanças climáticas, as nossas formas de estar no mundo, de criar nossas existências.

\section{VIDAS EM FLUXO, MUDANÇAS E ANDANÇAS}

Algumas questões que se levantam diante do cenário de Mudança Climática (MC) que afetam os currículos são: como estamos nos proliferando? Como estamos fazendo laços e alianças nesses tempos em que nossos gestos têm se dissolvido cada vez mais? Guattari (2017) diz que caminhamos para uma perda gradual dos nossos gestos; com os gestos, as palavras; com as palavras, a solidariedade; com a solidariedade, as outras espécies também têm desaparecido. As mudanças climáticas apontam suas urgências, ao mesmo que tornam urgentes as necessidades de conhecer e mitigar seus rastros, suas marcas. Entender que elas não se esgotam nos recursos naturais, mas que também permeiam nossas relações com as espécies humanas e não humanas, bem como nossas produções de formas

\footnotetext{
${ }^{4}$ As residências artísticas foram feitas por Fabíola Fonseca durante os processos de criação de suas obras, contudo nos juntamos para pensar e escrever este artigo. Logo, em alguns momentos usaremos o singular para fazer esta diferença que é apenas em relação à presença de um corpo físico no lugar. Nossas divagações nos conjugam aqui por e com este texto escrito a quatro mãos.
} 
de estar no mundo, nossas sociabilidades. Pensar nisso se conecta também em pensar a formação social que temos criado e, consequentemente, pensar nas produções dos desejos a partir dessas sociabilidades.

Isso porque o que chamamos de MC, apesar de se referir ao aumento da temperatura do nosso planeta, atravessa as nossas escolhas e, com isso, nossas relações. Não conseguimos falar de MC sem falar na forma como racismo, trabalho escravo e fascismo, por exemplo, conectam-se a esse cenário e geram aumento da temperatura global; tampouco sem falar na forma que somos subjetivados para isso. Ou, se continuarmos insistindo em fazer a leitura desse cenário apenas a partir dos dados técnicos, nos distanciaremos cada vez mais de outros cenários plausíveis para a sobrevivência e o convívio das espécies. Em linhas gerais, nossos racismos geram mão de obra barata, nossos fascismos geram e justificam uma grande exclusão social. Ambos se conectam com o axioma do lucro e da produtividade: a geração de riqueza para um grupo reduzido de pessoas não se faz sem que seja gerada miséria para um enorme grupo de pessoas.

Ressaltamos que entendemos as MC como um rizoma, no qual as linhas são todas conectáveis e podem se rearranjar a cada movimento. Esses rearranjos e conexões, Deleuze e Guattari chamam de agenciamento. “Um agenciamento é precisamente esse crescimento das dimensões numa multiplicidade que muda necessariamente de natureza à medida que ela aumenta suas conexões" (DELEUZE; GUATTARI, 2017a, p. 24). Logo, falar de mudanças climáticas não pode se esgotar em falarmos na nossa relação com os recursos naturais, balizando-os como mercadorias, como tem sido feito, mas também das nossas relações com seres vivos e não vivos, humanos e não humanos e da formação social que temos construído nessas linhas que têm sido puxadas e rearranjadas.

Encontramo-nos todos hoje em meio a um desequilíbrio biogeofísico do planeta que vamos descobrindo ser de uma dimensão inteiramente inusitada, não apenas para a civilização moderna, mas para a "civilização" de modo geral, e mesmo para a espécie Homo sapiens como um todo, bem como para grande parte das demais espécies viventes que compartilham conosco essa biosfera [...]. Sem contar o arrasamento, as poluições e contaminações dos ecossistemas, vão ser necessários provavelmente muitos milhões de anos para que o $\mathrm{CO}_{2}$ que lançamos na atmosfera e nos oceanos volte a se estabilizar como antes [...]. Enquanto isso, os mares já estão mais ácidos, partes imensas do Ártico, da Antártica e da Groelândia se desestabilizaram de maneira provavelmente irreversível, o nível dos oceanos sobe cada vez 
mais rapidamente, em uma velocidade que alguns dizem ser até mil vezes superior à taxa de fundo da extinção. (DANOWSKI, 2019, p. 86).

Danowski e Viveiros de Castro (2017) ressaltam as incertezas desse cenário no qual as coisas se deslocam fora de escala, de tal maneira que não conseguimos compreender ainda o que esperar ou que iremos presenciar. Temos experimentado ondas de calor, chuvas torrenciais, maremotos, tempestades de areia e não conseguimos prever tais eventos. Estamos todos expostos a isso, espécie humana e não humanas. Danowski (2019) diz que as MC colocam em xeque nossas relações e a forma que temos produzido nossas existências. Ela diz que há uma zona problemática porque, apesar de já estarmos sentindo seus efeitos, ninguém ainda sabe ao certo o "como fazer". Não há um caminho a ser seguido que nos leva para a certeza das soluções. O que nos resta é tatear possibilidades, inventar caminhos, experimentar percursos.

Recentemente, assistimos ao documentário chamado Estou me guardando para quando o carnaval chegar, de Marcelo Gomes (2019), que mostra a rotina dos trabalhadores de uma cidade no sertão pernambucano - Toritama, um centro de produção com mais de 20 milhões de peças produzidas por ano nas fábricas caseiras. É pela venda das peças que a maior parte dos moradores têm suas fontes de renda. O trabalho deles é visivelmente precarizado, recebem por peça produzida, não têm direitos trabalhistas, ficam longas horas cortando, costurando, tingindo as peças, escutando o barulho das máquinas de costura em locais pouco ventilados, apertados ou em suas casas. Trabalham o ano inteiro e só folgam no carnaval. Ainda assim, nas suas falas, esses trabalhadores alegam que, com essa forma de trabalhar, são empresários de si e não há ninguém dando ordem a eles.

Com isso, queremos dizer que, se quisermos pensar nas questões ambientais, precisamos também pensar na cadeia produtiva que envolve a transformação dos recursos naturais em mercadoria, nas consequências ambientais disso, nos modos de vida que têm gerado, nas novas dinâmicas que são estabelecidas com essas crescentes zonas de hiperexploração do trabalho e, sobretudo, na forma como essas subjetividades vão sendo produzidas dentro desse axioma que visa ao lucro. O que se conecta também em pensar a formação social que temos criado e, consequentemente, nas formas de produções dos desejos a partir dessas sociabilidades. Pautas imprescindíveis para um currículo que deseja proliferar vidas fora das lógicas da centralidade nos sujeitos humanos, 
exclusivamente para explorarmos um plano de imanente desconexão entre nós e os outros.

"Aliás, essa desconexão [entre o que somos e o que podemos ser] não se limita a uma condição subjetiva, de causas psicológicas e individuais (conscientes ou inconscientes) (DANOWSKI, 2019, p. 89). Ao encontro disso, Krenak (2019) fala que a gente vem sendo equalizado nos nossos desejos, nas nossas formas de estar no mundo, como se houvesse um jeito único de viver na Terra. Ele diz que há um investimento midiático que nos subjetiva e nos leva a ter jeitos similares de vivenciar o amor, a vida conjugal, os estilos de vida, hábitos de consumo, o ensino e nossas relações com a natureza. Estamos tendendo aos movimentos que não nos tiram do lugar, uma solidão não povoada, transformando a natureza em estatística, em medidas de utilidade, e abafamos as possibilidades de vê-la de outra forma. Estamos vivendo no axioma do lucro, da mercadoria.

Do ponto de vista das "ciências biológicas", mensuramos e distribuímos os seres vivos em reinos, em famílias, até chegarmos às espécies. Inventamos uma evolução linear e separamos pelas proximidades genéticas. Ensinamos e somos ensinados a perceber a natureza dessa forma, sempre distantes de nós, como se nós fôssemos uma espécie arrancada dela. Fazemos cladogramas, situamos as espécies e as encaixotamos em clados, dando a ideia errônea de que a história evolutiva daquela espécie fosse linear, por filiação e não englobasse suas relações com seres de outras espécies ou até mesmo não vivos. E, mesmo quando consideramos as relações ecológicas, elas já estão capturadas, descritas por um modo operandis padronizado dos seres vivos e com um objetivo previamente determinado. Qualquer relação que aparece tentamos enquadrar nessas referências. E, mesmo diante das limitações dessas referências utilitaristas, insistimos em fazer da vida que nos cerca uma história que só pode ser contada da mesma forma: o camaleão imita as cores do ambiente para se camuflar; um fungo se associa à alga para garantir a sobrevivência...

Perdemos a oportunidade de dançar com os cogumelos, como faz Anna Tsing (2015) em seu estudo antropológico The mushroom at the end of the world, ao nos falar da relação entre os imigrantes japoneses nos Estados Unidos que catam cogumelos e fazem disso linhas com suas formas de existir. Encaixamos os fungos na função de decompositores de matéria orgânica e não conseguimos sair disso. Talvez, considerando o contexto escolar, a função de decompositores 
seja logo superada pelo utilitarismo, a partir do qual são apresentadas as importâncias dos fungos que devem ser entendidas a partir da questão: como podem ser importantes para nós? Seja pelo viés da alimentação, da fermentação ou da possibilidade de causar doenças.

Talvez por temos cindido vida e vivo estejamos apaziguados com um ensino de biologia que trata os fenômenos em suas pretensas purezas naturais, no qual tudo é passível de previsibilidades, tudo está ordenado em fluxo contínuo e sucessivo, como se a vida e seus abalos estivessem fora do vivo. O que dá vida abala o vivo é sempre tratado como interferência, como algo exterior a ele, indesejado, um desvio no curso natural da história. Somente pensando o vivo fora dos domínios da vida (um vivo sem vida - que é pura realização de um processo orgânico, o vivo intocado) e a vida fora da materialidade (uma vida sem corpo - vida metafísica) é que podemos pensar uma vida vetorial, vida telos, cujo sentido já está dado na partida. Essa é a versão moral da vida. Com essa versão nos tem sido possível julgar e enquadrar práticas sociais (desmatamento e reflorestamento como boas e más práticas), inventar o normal e o patológico e demarcar seus limites, selecionar quem tem e quem não tem direito a vida. É essa a versão que usualmente sustenta o ensino de biologia. (CHAVES, 2018, p. 17).

Pautamos o ato de ensinar biologia em um currículo pré-programado que repele a vida, que cria categorias e que se fecha nisso. Questionamos: ensinamos biologia? Ensina-se biologia? Arrancamos do "[corpo - biológico ou não] tudo aquilo que lhe é mais próprio, sua dor no encontro com a exterioridade, sua condição de corpo afetado pelas forças do mundo" (PELBART, 2013, p. 31). $E$, diante desses impasses que têm aparecido cada vez mais nas pesquisas em educação e nas práticas docentes nas escolas, professores e pesquisadores da área de educação têm mergulhado em processos de pensar a construção de uma educação rizomática, um currículo nômade no qual os encontros vão alimentando as práticas, criando linhas, arrebentando outras.

É a partir dessa percepção de currículo que queremos pensar com as mudanças climáticas. Concordamos com Deleuze e Guattari (2016) quando eles dizem que pensar é criar, o que coloca em questão o currículo que vem sendo feito baseado na recognição, na qual os estudantes precisam memorizar conteúdos para mostrar que aprenderam.

Experimentar por andanças vagueantes é sair dessas referências e significações e abrir para outras possibilidades de nos relacionarmos com as coisas, 
com o mundo.

Acontece que criar não diz respeito a uma decisão arbitrária ou a um decreto. Fazer com que a verdade dependa de um ato de criação não é confiná-la no subjetivismo, submetê-la ao capricho de uma vontade individual (relativismo que, como se sabe, anularia a verdade). Deleuze mostra, ao contrário, que o ato de pensar põe necessariamente em crise a subjetividade, e que a necessidade, longe de atender aos votos de um sujeito pensante já constituído, só é conquistada quando o pensamento está fora de si mesmo, pensamento que só é absolutamente potente na ponta extrema de sua impotência. (ZOURABICHVILI, 2016, p. 47).

É importante que se consiga ver a aliança que a planta faz com o vento, que a flor faz com a abelha, que as raízes das plantas fazem com os fungos. Vinciane Despret (2016, p. 17) diz que "[...] nesses tempos de extinção, precisamos de outras histórias para nos ensinar a mudar nossa relação com o mundo, torná-lo menos violento, menos mecânico, menos dominador. Histórias que não seriam mais restritas a padrões econômicos ou de guerra". A Natureza, como dizem Deleuze e Guattari (2017b), funciona mais como anti-natureza, por operar entre os diferentes. Estamos falando das proliferações das espécies que vão criando mundo, colorindo, produzindo cheiros, sensações.

Desde os estudos sobre currículo e ensino com biologias, Guimarães e Krelling (2014) experimentaram a potência do pensar a partir da fabulação com os objetos de um laboratório científico. Compuseram com as crianças um outro mundo, um outro laboratório, uma outra forma de perceber a ciência. Desvendaram e produziram segredos guardados por aqueles objetos, criaram outras proliferações e outros segredos. Biologia, arte e educação: escolhemos esse caminho no qual podemos sentir cheiros, anseios, medos, coragens para tatearmos nas potências das coisas um ensino por vir, que nos desloque pelos encantamentos do Universo da biologia.

Qual a potência de uma folha? De um gafanhoto? De um fungo? Só saberemos se experimentarmos com eles.

\section{MODULAÇÕES EM DESLOCAMENTO}

Por onde passariam as linhas para o currículo experimentar os encontros potentes com as biologias que vibram nas mudanças climáticas? Ancoramos nas residências artísticas, que são metodologias bastante utilizadas no campo da arte. 
Nelas o artista vai para um espaço colaborativo, onde terá trocas e interações sociais com outros artistas, curadores, para que o experimentado incentive a sua produção. Há, portanto, um deslocamento embalado por essas novas experiências, o encontro com o outro, o escopo do tema escolhido e o local em que se realizará e, assim, espera-se que esse processo contribua para criações, para a formação e, sobretudo, para emancipar o pensamento. Tais propostas, usualmente, caracterizam-se por dinâmicas criadas pelo grupo em que experimentam um determinado tema de várias formas.

Marcondes (2019) diz que essas residências artísticas têm características diversas, podendo ou não serem financiadas pelas instituições que oferecem ou até cobrar taxas para os artistas selecionados; podem ser realizadas em ambientes diversos (sítios, ateliês, oficinas culturais, ambientes naturais etc.); podem ter como foco uma ou mais linguagens artísticas. Há uma gama de possibilidades que vem sendo abraçada, na medida em que a arte contemporânea passou também a ser impulsionada no mundo. O autor coloca em relevo que é preciso considerar que o movimento desse cenário de arte contemporânea convida artistas a abraçarem em suas obras a natureza política e transgressora da arte, a fazer com elas formas de posicionamentos em um mundo cheio de conflitos. Ao mesmo tempo, as obras de arte contemporâneas causam um frisson por levantarem questões sociopolíticas e ambientais, sobretudo porque também têm deixado para traz museus e galerias de arte como locais primordiais de exposição. Nisso, ruas, praças, espaços virtuais e outros espaços públicos têm sido palco de intervenções artísticas de diversas naturezas, colocando o público que transita por esses espaços também em contato com as obras.

As residências artísticas promovem fissuras para pensarmos com a arte, mas também as outras temáticas e áreas do conhecimento que podem ser embaladas por elas. Ainda assim, as produções acadêmicas sobre residências artísticas no campo da arte são escassas, conforme dito por Marcondes (2019), até porque, embora tenham sido impulsionadas pela arte contemporânea no começo da década de 1960, foi apenas nos últimos anos que ganharam força com novas propostas, financiamentos e temáticas variadas.

Destacamos aqui duas obras realizadas durante a residência artística no LabVerde, um programa de imersão artística na Floresta Amazônica que aborda ciência e arte.Uma delas é a de Paula Sampaio (@paulasampaio564) apresentada 
no Festival O Amanhã É Agora, em que a artista executa um projeto de documentação fotográfica dos trabalhadores imigrantes, majoritariamente, explorados na região das estradas da Amazônia, sobretudo na Belém-Brasília e na transamazônica, e cria conexões com partes de elementos naturais. Nas palavras da artista: "É meu destino percorrer esse corpo amazônico. Sua pele, tatuada de rios, florestas e rastros de seres de todo tipo... é na rota de longas e trágicas estradas da região que surgem os encontros". A outra artista, Aura Oura (@aoruaura), diz que "[...] é preciso ter cautela ao tentar lapidar uma pedra viva" e utiliza objetos inanimados e animais mortos que coloca em contato com partes do seu corpo para criar uma corpa-imagem e tensionar as condições caóticas de criação de vida no Antropoceno. As palavras das artistas foram transcritas de um post de convite para o festival no Instagram do LabVerde.

Nesse sentido, os artistas inventam relações entre organismos e máquinas, que vão além do utilitarismo, instrumentalismo e submissão, mas de uma dupla existência. Essas práticas só se dão pela relação constante de experimentações de simbioses e conjunções entre o orgânico e o inorgânico para pensar as novas interfaces naturais e artificiais, de inventar outros arranjos, experimentar e inventar outras práticas na/para contemporaneidade através dos trabalhos de alguns artistas da contemporaneidade. (SILVA, 2020, p. 195).

Em um dos textos da revista ClimaCom, Susana Dias (2020) experimenta uma residência artística e encontra um devir-floresta para conversar com as mudanças climáticas. Susana esboça-nos um currículo, aquele da experiência com uma floresta, ainda que dentro de uma sala de aula, em que vidas orgânicas, inorgânicas e virtuais pulsam, comunicam e contagiam-se. "Uma floresta interessa por ser um laboratório vivo do que pode se tornar um estar junto, por reunir modos heterogêneos de viver, sentir e pensar e deixá-los coexistir, promovendo relações aberrantes, parentescos impensados" (DIAS, 2020, p. 9). A autora interessa-se pelas conexões, pelas pontes, pelas sinapses e se distancia do pensamento em torno do indivíduo - o tal sujeito moldado -, indo para as populações, os fluxos, as relações entre os devires. "Não se trata mais de falar sobre as florestas, mas um perceber-fazer floresta por outros modos de existências sensíveis, de modos de existência fotográficos, pictóricos, escultóricos, cinematográficas, performáticos, de escrita etc." (DIAS, 2020, p. 16).

Conhecer as residências artísticas e a forma como elas instauram necessidades diante dessa paisagem movente com diferentes conflitos ambientais, sociais 
e políticos cintilou em nós. Os laboratórios de pesquisa tornaram-se parte dos ambientes de trabalho e foi nesse processo que conseguimos, ao mesmo tempo, aproximar-nos e deslocarmos nossos olhares com a ciência e com a arte. Nesse processo de pesquisar, nós nos enveredamos por entre produções artísticas nessa temática, as residências artísticas nos laboratórios e o convívio com cientistas, com as bancadas para experimentar protocolos. E o processo de produção do conhecimento científico tem nos apresentado uma potência de pensar outros currículos do ensino de biologia e das MC, na medida em que a intimidade com as vidas e as coisas que perambulam e habitam os laboratórios vai nos expandindo para outras formas de relações com elas.

Pensando a educação fora da pastorização, da condução, ela se coloca na ordem do heterogêneo, do múltiplo, do devir, para aquém e para além de métodos e de teorias totalizantes. Ela se coloca na ordem do acontecimento, do inconsciente, no fluxo dos problemas que fazem nascer o pensamento como criação, não como recognição. (CARVALHO; GALO, 2010, p. 299).

Um fluxo de problemas que se movimenta por entre algumas fissuras que temos encontrado nesse caminhar metodológico com as residências artísticas. Assim como Amanda Leite (2019, p. 771), entendemos "[...] que as residências artísticas operam como metodologia de trabalho e oportunizam exercícios de livre experimentação que desejam pensar, escrever, inventar e deslocar o corpo criativo a outros lugares, a outros modos de produzir pensamento e educação". As residências artísticas têm nos ajudado a perceber o ensinar como movimento e o pensar como ato de criar.

Para desenvolver as criações artísticas, é estabelecida uma rotina de idas ao laboratório durante um período de 3-4 meses. Nesse tempo, nada é definido a priori, "[...] uma vez que somos definidos pelos afectos que vivenciamos, não há nada que anteceda uma relação afectiva derivada de encontros ocasionais" (VINCl, 2018. p. 331). Intensificamos diálogos e aproximações com os pesquisadores e estudo sobre o objeto de pesquisa do laboratório. Mergulhamos nesse processo de produção do conhecimento, encontramos com ele nas linhas que nos emaranham e emancipam. Para tanto, é essencial a troca com os pesquisadores: aprendemos as lógicas científicas para escolher usar o ágar batata, ou ágar sangue, ou ágar mitilis até os conceitos mais complexos sobre a biologia dos fungos, a mosca da fruta como inseto modelo, as estratégias de vida, as manipulações 
feitas no laboratório. Acompanhamos alguns cientistas nas bancadas, para conhecer melhor as pesquisas, os testes que fazem, os protocolos que usam ou que usavam antes "desse aparelho chegar", como diziam. Temos criado relações não hierarquizadas nesse processo.

Ao mesmo tempo, elas/es participam da pesquisa, indicando possibilidades artísticas sobretudo quando trabalham com seres vivos que mudam a coloração dos meios de cultura; ou quando surgem nas placas de Petri formas e cores bonitas aos olhos deles; ou quando os cruzamentos entre as moscas produzem diferentes cores para os olhos delas. Ciência e arte criam conexões, entradas e saídas e, por entre elas, passam linhas que se entrelaçam e se arrebentam, rizomam-se. E é nesse encontro das linhas que formam um rizoma que as coisas perdem a necessidade dos nomes, do artigo definito, do verbo como palavra de ordem... é nessa rachadura produzida pelos encontros que nos deixamos habitar.

Ao encontro disso, Vinci (2018) diz que "[...] somos definidos pelos afectos que vivenciamos, não há nada que anteceda uma relação afectiva derivada de encontros ocasionais" (p. 331). E isso, pensado dentro do "[...] universo espinosano, contudo, a potência, poder ou não agir, não antecede a ação, mas the é imanente. Quanto mais um vivente experimenta, mais suscetivel às alegrias está e, por conseguinte, mais potência para agir pode vir a adquirir" (VINCI, 2018, p. 333). Experimentar outras biologias que nos tragam alegria, que nos coloquem e conectem a linhas de criação, que nos permitam enxergar as outras formas de vida em suas potências.

"Trata-se de um mundo de pura imanência, destituído de qualquer antecedência. Neste mundo, não há objetos ou sujeitos prévios, e as relações são sempre exteriores aos termos que comportam" (VINCI, 2018, p. 331). Encontramos cientistas se lançando em artes, vemos artistas se lançando em ciência. Olhamo-nos no meio disso e vemos pedaços sendo enxertados e arrancados, causando em nós movimentações que nos levam a transitar com outros seres, vistos distantes das utilidades que criamos para a existência deles. Bactérias transitando diante dos nossos olhos, criando alianças com outros seres e abrindo espaço para a convivência com outras formas de vida. Se não fossem elas habitando nossas peles, nossas entranhas, nada seríamos, talvez. Com a experimentação nas residências artísticas, criamos essas outras relações, que nos distanciam de parâmetros utilitaristas.

A arte, nesse sentido, é importante por sua atitude de recusa em relação aos valores instituídos, por seu interesse em, resgatando Artaud, dar um 
fim nos juízos vigentes ou, em outros termos, por sua atitude de recusa frente aos falsos problemas da cultura. $\mathrm{O}$ artista é um experimentador de pensamento, uma vez que toma certos signos e busca decifrá-los em sua heterogeneidade, elaborando, assim, mundos que não estão em conformidade com o real. Experimentação, portanto, nada mais é do que aprender a criar esses mundos outros, a partir dos encontros com signos diversos, e seria uma propriedade característica do fazer artístico arte, mais especificamente. (VINCl, 2018, p. 328).

A obra de arte Como falar com formigas ganhou consistência em uma residência artística em que acompanhávamos a pesquisa em um museu. Este era um lugar em que os cientistas nos apresentavam as coleções zoológicas e a importância delas dentro desse cenário de extinção das espécies. O processo de criação fez com que nos debruçássemos muito tempo a observar as formigas doceiras que andavam pela cozinha da casa no começo da quarentena. Foram feitos registros em vídeo e utilizadas pequenas gotas de mel como iscas para atraí-las, já que a nossa dinâmica de ficar mais tempo em casa findou por alterar a dinâmica delas, que passaram a ser vistas com menor frequência. Uma gota de mel era um convite ao banquete delas. E logo depois de um tempo servido, elas estavam lá, rodeando o mel como um desenho de sol ${ }^{5}$. Hora seguidas ali observando a forma como elas se comunicam pelo toque das antenas. Era uma tocando a antena da outra para dizer algo. Isso nos levou a pensar na história evolutiva delas, em que tiveram que lapidar a habilidade do tocar para existirem. E nossos questionamentos eram também voltados para as nossas existências, sobretudo naquele momento de crise sanitária em que nossos gestos de tocar uns aos outros foram alterados pela dinâmica de um mundo em pandemia. Questionamos com essa obra: se a gente pudesse falar feito formiga, como seriam nossos gestos?

Foi também em uma residência artística que elaboramos uma proposta educativa de observar o crescimento das raízes das estacas de plantas para criar um livro de artista ${ }^{6}$. As raízes têm sido pajeadas diariamente pelas cursistas que anotam seus registros em um caderno, desenham, fotografam. "Os afectos e as afecções são efeitos produzidos nas relações entre dois corpos ou mais, numa

\footnotetext{
${ }^{5}$ Você pode conferir essa foto no site pessoal de Fabíola Fonseca: www.proliferacoes.com ou no insta que alimento com as obras: @protocolofungo

${ }^{6}$ Você pode ver mais sobre esse curso no instagram: @liquenprojeto
} 
ordem de acaso ou encontro fortuito" (KROEF, 2018, p. 125). Uma aliança feita por entre raízes, mulheres, botânica e arte que arranca, das raízes observadas, outras delicadezas para criarmos mundos.

A experimentação artística seria uma busca por sentido, este não residiria em um alhures ou nos próprios objetos experimentados, mas sim nos encontros com os signos - compreendidos como aqueles que nos forçam a pensar, por conta de oferecerem elementos singulares a serem interpretados e capazes de obrigarmos a sair da mera condição de observador. Haveria uma violência no signo, atrelado ao seu caráter heterogêneo, que se manifestaria de três maneiras distintas (DELEUZE, 1988), quais sejam: em primeiro lugar, entre o signo emanado e o objeto emanador haveria uma diferença de nível ou, em outros termos, a presença de duas ordens de realidade convivendo em conflito; em segundo lugar, o signo apontaria sempre para outra coisa que não o próprio objeto do qual emana e que tampouco coincidiria com ele; e, por fim, o signo solicitaria uma resposta que jamais poderá coincidir com a pergunta por ele colocada. A violência do signo, em resumo, estaria atrelada ao fato dele não poder ser representado nem pelo objeto do qual emana, nem pela ideia que ele portaria virtualmente e tampouco pela resposta interpretativa por ele demandada. O signo escapa da ordem representacional, ao exigir uma interpretação incapaz de se conformar ao real ou as verdades estabelecidas a priori. As grades de leitura do mundo não servem para interpretar o signo, este exige a criação de uma lente própria para ser captado. (VINCl, 2018, p. 326).

As experimentações das residências surgem, portanto, como uma possibilidade de "[...] arranjamentos que produzem linhas de fuga, geram desvios do currículo num movimento do currículo-nômade" (KROEF, 2018, p. 114). São elas que traçam linhas de fuga e borram as fronteiras de um programa educativo organizado, estruturado em necessidades hegemônicas, e instauram, assim, o inusitado como possível, como nos diz a autora. Desconectam-se de valores instituídos a priori para lançar-se em deslocamentos. Mundos por vir.

Aos poucos, vemos a possibilidade de sair dos modos de conhecer e aprender com os quais nos ensinam a olhar para as coisas. Vamos criando outras formas de nos relacionar, porque traçamos fugas das categorizações impostas. "Habituamos a olhar as coisas como engenhos, esquecemos que estamos perante um organismo que nasce, respira e vive de trocas com a vizinhança" (COUTO, 2011, p. 53). As moscas transgênicas, fungos, formigas e raízes ganham outras potências nesse momento de criação, de invenção, de incerteza e de abertura quando um se 
faz sensível ao outro. E não foram só essas vidas. Cientistas também entram nessa possibilidade de criação de outras relações com a arte. Experimentamos outras possibilidades de existências, de relações e, com isso, adiamos o fim do mundo.

\section{EXPERIMENTAR E ADIAR}

Não estamos no mundo, tornamo-nos com o mundo, nós nos tornamos, contemplando-o. Tudo é visão, devir. Tornamo-nos universo. (DELEUZE; GUATTARI, 2016, p. 200).

Habitar um laboratório de ciência é passear por entre paredes e máquinas que nos levam a ver e sentir seres invisíveis, e nas residências artísticas temos experimentado com as outras vidas do laboratório. Passeamos por entre paredes, máquinas, reagentes e convivemos com os cientistas para que ressoem suas potências em nós. Nós nos abrimos para a potência desses encontros, suas reverberações, dos espaços que abrimos com a intimidade do convívio para repensar nossas relações tão modeladas, nossos modos de operacionalizar a vida e até mesmo de viver nossas vidas, criar linhas que passam por entre essas biologias inventivas.

A residência artística é, metodologicamente, esse momento de experimentar, de provocar quebras nas linhas segmentares e liberar as diferenças. E com essas percepções que pensamos ser capazes de inventar quem podemos ser. Assim temos traçado linhas de fuga, uma linha que não tem direção a priori e que, portanto, pode ser invadida pelas mais diversas intensidades. Daí as necessárias doses de prudência. "The line of flights, to the contrary, is intransitive: it carries on" (INGOLD, 2011, p. 14) [A linha de fuga, ao contrário, é intransitiva: ela segue]".

A linha de fuga é isso que em um dado momento, provocada por um agenciamento, desterritorializa-se de um regime de signos e começa a correr por si só, abrindo-se para novas possibilidades. Não há como prever a direção da linha de fuga. O currículo-experimentação acontece por entre essas linhas vagueantes, criando corpos.

Experimentamos diferentes entradas, borramos as fronteiras que foram construídas para separar e hierarquizar espécies humanas de não humanas e conjugamos cientistas e artistas para adiarmos o fim do mundo. Questionamos: 
o que pode uma formiga, um fungo, uma raiz, um atravessamento entre ciência e arte? De mãos dadas com Spinoza, respondemos: só saberemos se experimentarmos com eles.

No final das contas, a gente quer ter histórias para contar.

\section{REFERÊNCIAS}

AMORIM, Antônio Carlos Rodrigues. Diagramas para um currículo-vida. Revista humanidades \& inovação, Tocantins, v. 8, n. 5, p. 406-420. 2020.

CHAVES, Silvia Nogueira. Os sem sentidos da vida ou: a vida não tem sentido, invente o seu. In: RAMOS, Mariana B.; TRÓPIA, Guilherme; OLIVEIRA, Mário Cezar Amorim (Org.). Práticas diferenciadas em ensinos e biologias. Campinas, SP: Mercado de Letras, 2018.

CARVALHO, Alexandre Filordi; GALO, Sílvio. Do sedentarismo ao nomadismo: intervenções para pensar e agir de outros modos em educação. ETD - Educação Temática Digital, Campinas, v. 12, n. 1, p. 280-302, jul./dez. 2010.

COUTO, Mia. E se Obama fosse africano? São Paulo: Companhia das letras, 2011.

DANOSWI, Deborah. Mundos sob os fins que vêm. [S.I.]: Conexões, 2019.

DANOSWI, Deborah; VIVEIROS DE CASTRO, Eduardo. Há mundos por vir? Desterro. Florianópolis: Instituto Socioambiental, 2017.

DELEUZE, Gilles. Dois regimes de loucos. São Paulo: Editora 34, 2016.

DELEUZE, Gilles; GUATTARI, Félix. Mil Platôs: capitalismo e esquizofrenia. São Paulo: Editora 34, 2017a. V. 1.

DELEUZE, Gilles; GUATTARI, Félix. Mil Platôs: capitalismo e esquizofrenia. São Paulo: Editora 34, 2017b. V. 4.

DELEUZE, Gilles; GUATTARI, Félix. O que é filosofia? Rio de Janeiro: Editora 34, 2016.

DESPRET, Vinciane de Oliveira, Tradução de Cícero de Oliveira. O que diriam os animais se... Belo Horizonte: Chão de Feira, 2016. (Cadernos de Leitura n. 45).

DIAS, Susana. Perceber-fazer floresta: a aventura de entrar em comunicação com um mundo inteiro vivo. Revista ClimaCom, Campinas, ano 7, n. 17, 2020. Disponível em: http:// climacom.mudancasclimaticas.net.br/susana-dias-florestas/. Acesso em: 30 jul. 2020. 
GOMES, Marcelo (Dir.). Estou me guardando para quando o carnaval chegar. Documentário. 2019.

GUATTARI, Félix. As três ecologias. Campinas, SP: Papirus, 2017.

GUIMARÃES, Leandro Belinaso; KRELLING, Aline Gevaerd. Os objetos das ciências: imaginações em uma experiência de ensino. Revista da SBEnBio, São Paulo, v. 1, p. 467987, 2014. [V ENEBIO VI EREBIO Regional].

HOLZMEISTER, Ana Paula Patrocínio; SILVA, Sandra Kretli; DELBONI, Tânia Mara Zanotti Guerra Frizzera. Por um currículo nômade: entre artistagens e invencionices. Currículo sem Fronteiras, [s.I.], v. 16, n. 3, p. 416-28, 2016.

INGOLD, Tim. Being alive: Essays on movement, knowledge and description. [s.I.]: Taylor \& Francis, 2011.

KRENAK, Ailton. Ideias para adiar o fim do mundo. São Paulo: Editora Companhia das letras, 2019.

KROEF, Ada. Currículo-nômade: sobrevoos de bruxas e travessia de piratas. Fortaleza: EdUECE: 2018.

LEITE, Amanda Mauricio Pereira. Residência artística: cartografias inventivas e o DevirPlanta. Revista Observatório, Palmas, v. 5, n. 4, p. 771-6, jul. 2019.

MARCONDES, Guilherme. Deslocamento, formação e legitimação: uma análise de programas de residência artística no Brasil. Caderno CRH, Salvador, v. 32, n. 87, 2019. Disponível em: https://doi.org/10.9771/ccrh.v32i87.30772. Acesso em: 26 ago. 2021.

ORLANDI, Luiz. Um gosto pelos encontros. Territórios de Filosofia (blog), [s.l.], [s.d.]. Disponível em: https://territoriosdefilosofia.wordpress.com/2014/12/29/um-gosto-pelosencontros-luiz-orlandi/. Acessado em: 26 ago. 2021.

PELBART, Peter. O avesso do niilismo: cartografias do esgotamento. São Paulo: n. 1 Edições, 2013.

SILVA, Antônio Almeida. Natureza, organismos e máquinas para o amanhã - encontros inesperados entre arte, ciência e filosofia. Linha Mestra, Campinas, n. 41, p. 192-203, 2020.

SILVA, Antônio Almeida; AMORIM, Antonio Carlos R. Poética do arquivar: didáticas dos despropósitos entre a arte e a natureza. Revista Teias, [s.I.], v. 21, n. 63, p. 324-39, out./ dez. 2020. 
TSING, Anna Lowenhaupt. The mushroom at the end of the world: on the possibility of life in capitalist ruins. [s.l.]: Princeton University Press, 2015.

VINCl, Christian Fernando Ribeiro Guimarães. O conceito de experimentação na filosofia de Gilles Deleuze. Sofia, [s.I.], v. 7, n. 2, p. 322-42, 2018.

ZOURABICHVILI, François. Deleuze: uma filosofia do acontecimento. Tradução de Luiz B. L. Orlandi. São Paulo: Editora 34, 2016.

\section{Sobre os autores:}

Fabíola Fonseca: Pós-doutoranda em Educação na Unicamp e pós-doutora em Artes pela Universidade Federal do Ceará. Doutora em Educação pela Universidade Federal de Uberlândia e doutorado-sanduíche em Harvard. Mestre em Ensino de Ciências e Matemática pela Universidade Federal de Goiás (UFG). Graduação em Ciências Biológicas (licenciatura e bacharelado) pela UFG. E-mail: fabiologa@gmail.com, Orcid: https://orcid.org/0000-0001-6349-1503

Antônio Carlos Rodrigues de Amorim: Pós-Doutor pela Escola de Comunicação do Goldsmiths College da Universidade de Londres. Doutor e mestre em Educação pela Universidade Estadual de Campinas. Graduado em Biologia pela Universidade Federal de Viçosa. Professor Associado II (MS-5.2) na Universidade Estadual de Campinas, no Departamento de Educação, Conhecimento, Linguagem e Arte. E-mail: acamorim@unicamp.br, Orcid: https://orcid.org/0000-0002-0323-9207

Recebido em: 10/09/2021

Aprovado em: 14/09/2021 
